\title{
Improving LLIN utilization and coverage through an innovative distribution and malaria education model: a pilot study in Okavango Sub-District, Botswana
}

\author{
Simon Chihanga ${ }^{1}$, Allison Tatarsky²* ${ }^{*}$ HT Masendu ${ }^{1}$ D Ntebela ${ }^{1}$, Tjantilili Mosweunyane ${ }^{1}$, Mpho Motlaleng ${ }^{1}$, \\ Godira Segoea ${ }^{1}$, Justin M Cohen ${ }^{2}$, Mercy Puso ${ }^{3}$, Bosiela Segogo ${ }^{4}$, Tshepo Andina ${ }^{4}$
}

From Challenges in malaria research

Basel, Switzerland. 10-12 October 2012

\section{Background}

The Botswana Malaria Indicator Survey in 2007 indicated remarkably low ITN coverage and usage rates of $9.4 \%$ and $5.3 \%$, respectively. To achieve universal coverage of LLINs, optimize uptake, and catalyze Botswana toward its 2015 goal of elimination, Botswana tested a new delivery model to replace its revolving fund scheme of selling subsidized nets to communities at risk.

\section{Materials and methods}

Okavango Sub-District experienced the highest malaria burden in the country (36\% of total burden) and was thus chosen as the pilot site. After comprehensive training, sub-district health staff distributed 32,000 LLINs free of charge door-to-door in 2009 and an additional 6,500 LLINs in 2010 and offered hanging assistance with kits of hooks and strings to households. All nets distributed were mapped by household. Both distributions were supported by health education campaigns, including household visits, roadshows, and calendar posters. Two surveys in 2009 and 2010 evaluated pilot outcomes using a structured questionnaire to interview 557 and 362 randomly selected households in Okavango. Findings from the pilot study informed scale up of LLINs throughout Botswana.

\section{Results}

The pilot successfully increased LLIN ownership in Okavango from $13 \%$ of households owning at least one ITN in 2007 to $89 \%$ of households owning at least one

\footnotetext{
${ }^{2}$ Clinton Health Access Initiative, Boston, Massachusetts, USA

Full list of author information is available at the end of the article
}

LLIN in 2009 and 94\% in 2010. LLIN usage also improved markedly from $5.3 \%$ of residents sleeping under an ITN in 2007 to $38 \%$ of residents sleeping under an LLIN in 2009 and $46 \%$ in 2010. In 2009, 73\% of LLINs were immediately hung with the assistance of distributors, and the probability of using an LLIN was $13 \%$ higher if households were assisted in hanging the LLINs. Households with a visible poster were $26 \%$ more likely to use an LLIN, and subsequent health education visits were significantly associated with higher usage $(\mathrm{p}=0.0005)$ - after no visits, $64 \%$ of nets were used while after three visits, $83 \%$ of nets were used. The majority of respondents received their malaria messages from LLIN distributors, health talks at clinics, and visits by health educators, indicating the critical role of door-to-door visits in increasing awareness about malaria and LLINs.

An intra-household analysis found that smaller households generally owned enough LLINs to cover all household members but larger households did not receive enough nets, indicating unequal distribution of LLINs. Moreover, in households with $100 \%$ coverage, $67 \%$ of residents used an LLIN in 2010 - a substantially higher rate than the district-wide rate of $46 \%$ that does not take into account whether households actually owned enough nets to use them.

Clinical malaria cases declined from 6,446 in 2008 to 22 in 2011 and confirmed cases declined from 183 to 15 . Alongside ongoing IRS, more robust implementation of parasitological diagnosis, and other interventions, the pilot was associated with a substantial decline in malaria cases in Okavango. 


\section{Conclusion}

Overall, the pilot achieved mass free distribution to over 64,000 individuals and significantly increased LLIN ownership and usage. Lessons learned from this pilot informed distribution of additional LLINs to all at risk areas in Botswana and this model was brought to scale successfully.

\section{Acknowledgements}

We are grateful to Malaria No More US, Malaria No More UK, and UNICEF for funding this pilot project.

\section{Author details}

${ }^{1}$ National Malaria Programme, Ministry of Health, Gaborone, Botswana.

${ }^{2}$ Clinton Health Access Initiative, Boston, Massachusetts, USA. ${ }^{3}$ UNICEF,

Gaborone, Botswana. ${ }^{4}$ District Health Management Team, Ministry of Health,

Okavango Sub-District, Botswana.

Published: 15 October 2012

doi:10.1186/1475-2875-11-S1-P95

Cite this article as: Chihanga et al.: Improving LLIN utilization and coverage through an innovative distribution and malaria education model: a pilot study in Okavango Sub-District, Botswana. Malaria Journal 2012 11(Suppl 1):P95.

Submit your next manuscript to BioMed Central and take full advantage of:

- Convenient online submission

- Thorough peer review

- No space constraints or color figure charges

- Immediate publication on acceptance

- Inclusion in PubMed, CAS, Scopus and Google Scholar

- Research which is freely available for redistribution

Submit your manuscript at www.biomedcentral.com/submit 